\title{
Polyethylene Materials with In-Chain Ketones from Catalytic Copolymerization
}

\author{
Maximilian Baur ${ }^{1}$, Fei Lin ${ }^{1}$, Tobias O. Morgen ${ }^{1}$, Lukas Odenwald $^{1}$ and Stefan Mecking ${ }^{1 *}$ \\ ${ }^{1}$ Chair of Chemical Materials Science, University of Konstanz, Department of Chemistry, Universitätsstraße 10, 78457 Kon- \\ stanz, Germany.
}

\begin{abstract}
The world's most important plastic, polyethylene, consists of inert hydrocarbon chains. An introduction of reactive polar groups in these chains is much sought-after, to overcome the problematic environmental persistency and enhance compatibility with other materials. However, with state of the art catalytic polymerization processes this has not been possible. Here, we show how a low density of individual in-chain keto groups can be generated in the high molecular weight polyethylene chains by catalytic copolymerization with carbon monoxide. Most importantly, the desirable materials' properties of high density polyethylene (HDPE) are retained. Processing can be performed by common injection molding and mechanical characteristics are on a par.
\end{abstract}

\section{Introduction}

Plastics materials are used on a vast scale, and they are an essential component of any modern technology. Polyethylene is the most important polymer material by scale. It combines facile processing and low-cost production with excellent mechanical properties. ${ }^{1}$ The latter arise from crystalline ordering of stretched hydrocarbon chains. This is particularly pronounced for HDPE (high density polyethylene), as it is composed of linear chains devoid of branches that would disturb this crystalline packing. ${ }^{2}$ Their hydrocarbon nature also makes polyethylenes hydrophobic and apolar. They will not easily adhere to polar materials like metals or wood. Due to the chemically inert nature of the hydrocarbon chains, polyethylenes are not susceptible to degradation reactions. This renders them persistent when released to the environment.

A possible approach to in-chain functionalized crystalline polyethylene materials is catalytic copolymerization with carbon monoxide, in theory. The resulting keto groups in the polyethylene chain can provide an array of desirable reactivities, including photodegradability as demonstrated for branched LDPEs (low density polyethylenes) with ca. $1 \mathrm{~mol} \%$ of keto groups from free-radical high pressure copolymerization. ${ }^{3-5}$ Due to their ability to accomodate into the polyethylene crystal lattice, ${ }^{6}$ low concentrations of keto groups are anticipated to not disturb the crystalline order in linear polyethylenes.

However, such materials have remained elusive to date despite numerous efforts. The much stronger binding of carbon monoxide $(\mathrm{CO})$ vs. ethylene monomer to the catalyst prevents consecutive incorporation of olefin. ${ }^{7}$ Thus, rather than a polyethylene chain, alternating polyketones are formed. These are high-melting engineering thermoplastics with entirely different applications and processing properties than polyethylenes. ${ }^{8}$

We report how the long-sought non-alternating catalytic copolymerization of ethylene and $\mathrm{CO}$ can be achieved with Ni(II) catalysts. Materials with a desirable low content of keto groups in high molecular weight polyethylene chains are formed, that can be melt processed and feature tensile properties like commercial HDPE.

\section{Results and Discussion}

Considering guidelines for catalyst choice and design, compatibility with polar reagents is an essential prerequisite. This excludes traditional electron-deficient $\mathrm{d}^{0}$-metal sites, as used in production of polyolefins ${ }^{1}$, which are deactivated by polar molecules like carbon monoxide. In fact, quenching with carbon monoxide is an established method to deactivate such olefin polymerization catalysts. ${ }^{9}$ Catalytic processes involving $\mathrm{CO}$, such as olefin carbonylation, generally rely on $\mathrm{d}^{8}$-metal centers, ${ }^{10}$ and the aforementioned alternating polyketones are produced commercially with cationic palladium catalysts. ${ }^{8}$ Further, the strong binding affinity of $\mathrm{CO}$ - widely used as a ligand in organometallic chemistry - has to be controlled. Especially irreversible displacement of other essential ligands, thus destroying active sites, must be prevented. In addition, the coordination of $\mathrm{CO}$ or formed keto-groups in the growing chain can potentially block coordination sites reversibly for further chain growth. Most importantly, the kinetic preference for $\mathrm{CO}$ incorporation, which promotes the formation of alter- 
nating polyketones, needs to be overcome. Note that in this sense the target CO copolymerizations are opposite to catalytic copolymerizations of ethylene with polar vinyl comonomers like acrylates $^{11-14}$ in which the comonomer reactivity can be problematically low.

These arguments underline neutral late transition metal catalysts with strongly bound chelating ligands as promising objective. Compared to the common cationic polymerization catalysts, in neutral active sites the preference for binding of $\mathrm{CO}$ vs. other ligands, including olefinic mono- mer, is less pronounced. Indeed, the only precedence for the occurence of consecutive ethylene insertions in $\mathrm{CO}$ copolymerization has been observed with neutral phosphinesulfonato palladium catalysts. ${ }^{15-18}$ However, low molecular weight brittle waxes with $\mathrm{M}_{\mathrm{n}} \leq 3.000 \mathrm{~g} \mathrm{~mol}^{-1}$ (and likely heterogeneous compositions) were formed ${ }^{19}$ and no polyethylene plastics materials could be obtained despite extensive studies by different joint industrial and academic ventures.

\begin{tabular}{|c|c|c|c|c|c|c|c|c|c|c|c|c|}
\hline$\#$ & Cat. & $\begin{array}{c}\mathbf{T} \\
{\left[{ }^{\circ} \mathbf{C}\right]}\end{array}$ & $\underset{[\text { bar] }}{\mathbf{p}}$ & $\begin{array}{c}\mathbf{t} \\
{[\mathbf{m i n}]}\end{array}$ & $\begin{array}{c}\text { CO in feed } \\
{[\mathrm{mol} \%]^{\mathrm{b}}}\end{array}$ & $\begin{array}{c}\text { yield } \\
{[g]}\end{array}$ & TOF $^{\mathrm{c}}$ & $\begin{array}{c}\chi^{\mathrm{d}} \\
{[\mathrm{mol} \%]}\end{array}$ & $\begin{array}{c}\mathbf{I} / \mathbf{N A} / \mathbf{A}^{\mathrm{e}} \\
{[\mathbf{m o l}-\%]}\end{array}$ & $\begin{array}{c}M_{\mathrm{n}}^{\mathrm{f}} \\
{\left[10^{3} \mathrm{~g} \mathrm{~mol}^{-1}\right]}\end{array}$ & $\mathbf{M}_{\mathbf{w}} / \mathbf{M}_{\mathbf{n}}{ }^{\mathbf{f}}$ & $\begin{array}{c}T_{m}\left[{ }^{\circ} \mathrm{C}\right] \\
(\% \text { Cryst })^{g}\end{array}$ \\
\hline 1 & 1 & 50 & 10 & 60 & 0.2 & 0.06 & 0.2 & $50^{\mathrm{h}}$ & $0 / 0 / 100^{\mathrm{h}}$ & n.d. ${ }^{\mathrm{h}}$ & n.d. ${ }^{\mathrm{h}}$ & $243^{i}$ \\
\hline 2 & 2 & 100 & 5 & 10 & 0.2 & 0.80 & 15.6 & $0.3(0.4)$ & $69 / 11 / 20$ & 54 & 1.7 & $133(71)$ \\
\hline 3 & 2 & 100 & 5 & 60 & 0.2 & 2.07 & 7.41 & $0.3(0.4)$ & $70 / 22 / 8$ & 102 & 1.5 & $135(66)$ \\
\hline 4 & 2 & 100 & 5 & 120 & 0.2 & 4.26 & 7.61 & $0.3(0.3)$ & $79 / 21 / 0$ & 140 & 1.6 & $134(68)$ \\
\hline 5 & 2 & 110 & 5 & 60 & 0.2 & 1.07 & 3.81 & $0.5(0.5)$ & $61 / 27 / 12$ & 84 & 1.7 & $133(65)$ \\
\hline 6 & 2 & 120 & 5 & 30 & 0.2 & 0.06 & 0.41 & 1.7 (1.7) & $31 / 49 / 20$ & 3 & 8.9 & $110(65)$ \\
\hline 7 & 2 & 100 & 40 & 10 & 0.2 & 1.20 & 23.4 & $1.1(2.7)$ & $9 / 37 / 54$ & 42 & 2.9 & $133(68)$ \\
\hline 8 & 2 & 70 & 40 & 90 & 0.2 & 0.05 & 0.12 & $50^{\mathrm{h}}$ & $0 / 0 / 100^{\mathrm{h}}$ & n.d. ${ }^{\text {h }}$ & n.d. ${ }^{\text {h }}$ & $228^{\mathrm{i}}$ \\
\hline 9 & 2 & 100 & 5 & 120 & 0.6 & 1.98 & 3.53 & $0.8(1.1)$ & $32 / 36 / 32$ & 147 & 1.8 & $135(62)$ \\
\hline 10 & 2 & 100 & 10 & 60 & 0.6 & 2.35 & 8.39 & $0.6(1.4)$ & $27 / 33 / 39$ & 154 & 1.9 & $134(63)$ \\
\hline 11 & 2 & 100 & 10 & 120 & 0.6 & 3.01 & 5.38 & $0.6(1.3)$ & $27 / 27 / 46$ & 210 & 1.8 & $138(61)$ \\
\hline 12 & 2 & 100 & 10 & 240 & 0.6 & 3.31 & 2.95 & $0.6(1.0)$ & 43 / 33 / 24 & 216 & 1.8 & $136(60)$ \\
\hline 13 & 2 & 100 & 5 & 120 & 2.6 & 0.06 & 0.08 & $50^{\mathrm{h}}$ & $0 / 0 / 100^{\mathrm{h}}$ & n.d. ${ }^{\mathrm{h}}$ & n.d. ${ }^{\text {h }}$ & $230^{\mathrm{i}}$ \\
\hline 14 & 5 & 100 & 5 & 120 & 2.6 & 0.03 & 0.06 & $50^{\mathrm{h}}$ & $0 / 0 / 100^{\mathrm{h}}$ & n.d. ${ }^{\mathrm{h}}$ & n.d. ${ }^{\text {h }}$ & $228^{\mathrm{i}}$ \\
\hline 15 & 5 & 100 & 5 & 60 & 0.2 & 1.04 & 3.73 & $0.4(0.4)$ & $62 / 29 / 9$ & 88 & 1.6 & $133(70)$ \\
\hline 16 & 3 & 100 & 5 & 120 & 0.6 & 0.05 & 0.08 & $50^{\mathrm{h}}$ & $0 / 0 / 100^{\mathrm{h}}$ & n.d. ${ }^{\text {h }}$ & n.d. ${ }^{\text {h }}$ & $229^{\mathrm{i}}$ \\
\hline 17 & 4 & 100 & 5 & 120 & 0.6 & 1.13 & 2.02 & $1.0(1.4)$ & $21 / 29 / 49$ & 60 & 1.7 & $133(69)$ \\
\hline 18 & 5 & 100 & 5 & 120 & 0.6 & 0.26 & 0.46 & $3.7(4.4)$ & $28 / 34 / 38$ & 84 & 1.7 & $134(63)$ \\
\hline 19 & 6 & 100 & 5 & 120 & 0.6 & 0.44 & 0.79 & $1.6(3.0)$ & $7 / 34$ / 59 & 45 & 1.6 & $133(69)$ \\
\hline 20 & 7 & 100 & 5 & 120 & 0.6 & 0.82 & 1.47 & $1.1(2.5)$ & $18 / 33 / 49$ & 90 & 1.7 & 135 (67) \\
\hline 21 & 8 & 100 & 5 & 120 & 0.6 & 0.01 & 0.02 & $50^{\mathrm{h}}$ & $0 / 0 / 100^{\mathrm{h}}$ & n.d. ${ }^{\text {h }}$ & n.d. ${ }^{\mathrm{h}}$ & $232^{\mathrm{i}}$ \\
\hline 22 & 1 & 90 & 40 & 60 & $0.1^{\mathrm{m}}$ & 0.05 & 0.2 & $50^{\mathrm{h}}$ & $0 / 0 / 100^{\mathrm{h}}$ & n.d. ${ }^{\text {h }}$ & n.d. ${ }^{\text {h }}$ & $240^{\mathrm{i}}$ \\
\hline $23^{\mathrm{k}}$ & 2 & 100 & 5 & 20 & - & 10.8 & 231.2 & - & - & 17 & 1.9 & $131(71)$ \\
\hline $24^{\mathrm{k}}$ & 2 & 70 & 10 & 10 & - & 3.16 & 135.1 & - & - & 548 & 2.3 & $138(58)$ \\
\hline
\end{tabular}

${ }^{\mathrm{a}}$ Reaction conditions: $10 \mu \mathrm{mol}$ precatalyst loading, $100 \mathrm{~mL}$ of toluene, $500 \mathrm{rpm}$ pitched blade stirrer. ${ }^{\mathrm{b}} \mathrm{Carbon}$ monoxide content in the feed gas. ${ }^{\mathrm{c}} \mathrm{TOF}$ given in units of $10^{3} \mathrm{~mol}\left[\mathrm{C}_{2} \mathrm{H}_{4}\right] \mathrm{mol}^{-1}[\mathrm{Ni}] \mathrm{h}^{-1} .{ }^{\mathrm{d}}$ Carbon monoxide incorporation determined by IR spectroscopy. In brackets: Carbon monoxide incorporation calculated from ${ }^{13} \mathrm{C}$ NMR spectroscopy by integration of the ${ }^{13} \mathrm{C}$ labeled $\mathrm{C}=\mathrm{O}$ signals in relation to the overall integral, considering natural abundance of ${ }^{13} \mathrm{C}$ vs. ${ }^{12} \mathrm{C}$. ${ }^{\mathrm{e}} \mathrm{I}$ :isolated carbonyls, NA: non-alternating adjacent carbonyls (cf. Fig. 2 for specification), A: alternating polyketone segments. Determined by ${ }^{13} \mathrm{C}$ NMR spectroscopy. ${ }^{\mathrm{f}}$ Determined by GPC in 1 ,2-dichlorobenzene at $160^{\circ} \mathrm{C}$ via universal calibration vs. polystyrene standards. ${ }^{\mathrm{g}}$ Determined by DSC, second heating cycle. ${ }^{\mathrm{h}}$ Alternating polyketone obtained. ${ }^{\mathrm{i}}$ Observed in first heating cycle. ${ }^{\mathrm{k}} 5 \mu \mathrm{mol}$ precatalyst loading. ${ }^{\mathrm{m}} 0.05$ atm CO introduced to reactor prior to ethylene addition, $200 \mathrm{~mL}$ toluene, catalyst precursor added by means of a dosing pump after pressurization and heating to reaction temperature. This procedure was used to account for the limited temperature stability of $\mathbf{1}$. 
Neutral N,O-coordinated salicylaldiminato and P,Ocoordinated phosphinoenolato $\mathrm{Ni}(\mathrm{II})$ catalysts in ethylene homopolymerization can produce linear semicrystalline PE with several million $g$ mol $^{-1}$ molecular weight. ${ }^{20}$ To favor non-alternating chain growth, high polymerization temperatures are also expected to be favorable. For the general case of two competing pathways, the preference for the energetically favored one decreases with increasing temperature according to $\mathrm{k}_{\mathrm{a}} / \mathrm{k}_{\mathrm{b}} \sim \exp \left(\Delta \Delta \mathrm{G}^{\neq} / \mathrm{RT}\right)$ assuming a given difference $\Delta \Delta G^{\ddagger}$ between the barriers for both pathways. The robust nature of $\mathrm{P}, \mathrm{O}$-coordinated nickel(II) catalysts is advantageous in this regard. They are applied at 140 ${ }^{\circ} \mathrm{C}$ for industrial ethylene oligomerization. ${ }^{21}$ However, due to their propensity for chain transfer by $\beta$-hydride elimination events, traditional P,O-coordinated catalysts even at lower reaction temperatures yield oligomers or low molecular weight polymers with $\mathrm{M}_{\mathrm{n}}<10^{4} \mathrm{~g} \mathrm{~mol}^{-1} .^{22-24}$ Only recently this long prevalent picture has been revised by the finding that appropriate bulky substituents can strongly suppress chain transfer to afford high molecular weight polyethylenes. $^{25,26}$

Notwithstanding the literature consensus that such catalysts are rapidly deactivated by $\mathrm{CO}$ and at most form only alternating polyketones with low activity, ${ }^{23,27}$ a state-of-theart salicylaldiminato (1) and phosphinophenolato catalyst precursor (2) were exposed to ethylene (E)/CO mixtures with low partial pressures of CO (Table 1), at polymerization temperatures found to be optimum in the established ethylene polymerizations with these catalysts. With $\mathbf{1}$, only small amounts of polymer were obtained even at an E/CO ratio of $>10^{2}$ (entry 1 ). The polymer product features the IR spectrum of an alternating polyketone. By contrast, with 2 substantial amounts of a polymer were obtained which features IR bands of polyethylene and a carbonyl band with a distinctly different wavelength compared to an alternating polyketone (entry 2, Fig. 2b).

Encouraged by these findings, a series of novel and also state-of-the art known neutral P,O-chelated catalyst precursors with bulky substituents on the phenolate moiety as well as aryl groups shielding one or both apical positions were explored (Figure 1. For details of synthesis and full characterization data cf. the Supporting Information, SI). Notably, catalyst precursors $\mathbf{2}$ - $\mathbf{7}$ are polymerization active in the presence of $\mathrm{CO}$ and, at high $\mathrm{E} / \mathrm{CO}$ ratios on the order of 100 , form polymers that are not alternating polyketones according to IR spectroscopy (Table 1).

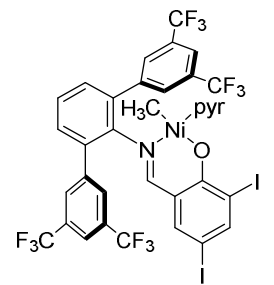

1

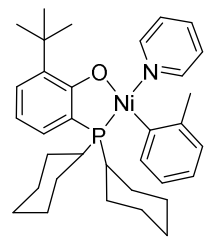

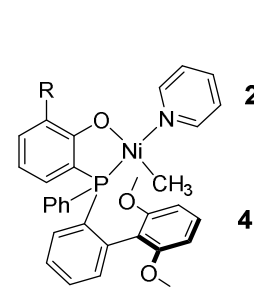

2: $\mathrm{R}=$<smiles>Fc1c(F)c(F)c(F)c(F)c1F</smiles>

$R=$<smiles>CC(C)(C)c1cc(C(F)(F)F)cc(C(F)(F)F)c1</smiles>

5

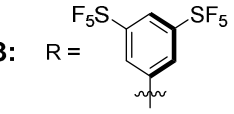

: $\mathrm{R}$

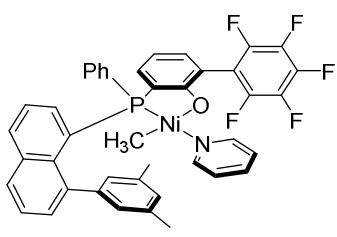

8

Fig. 1. Catalyst precursors studied. Salicylaldiminato complex 1, and phosphinephenolato complexes $\mathbf{2}$ to 8 .

Polymer microstructure and materials properties. The microstructure of the novel polymers was elucidated by ${ }^{13} \mathrm{C}$ NMR spectroscopic methods. To enhance sensitivity, copolymers from pressure reactor experiments with ${ }^{13} \mathrm{CO}$ were utilized. By a combination of $1 \mathrm{D}$ and 2D NMR methods and reference to literature data, ${ }^{1} \mathrm{H}$ and ${ }^{13} \mathrm{C}$ NMR spectra could be assigned fully (cf. Supporting Information, SI, for details). This reveals the presence of isolated ketone groups in the polyethylene chain (Fig. 2a). Further, nonalternating motifs of ketone groups in proximate positions along the chain can be differentiated, and alternating motifs are observable. Most notably, at desirable values of the $\mathrm{CO}$ incorporation of ca. $1 \%$, the majority of keto groups are not alternating, and moreover amongst these the isolated keto groups prevail. The overall keto contents determined by quantitative NMR spectroscopy are confirmed by IR spectroscopy (Table 1 and Fig. 2b. For details of reference data and discussion of the IR spectra of keto-functionalized polyethylenes $\mathrm{cf}$. the SI). As anticipated, these in chain keto-motifs do not compromise the desirable materials properties of polyethylene. Wide angle X-ray scattering (WAXS) diffractograms of the materials are virtually identical to that of HDPE (Fig. 3a), underlining the solid-state structure is retained. Also, melting and crystallization points are virtually unaltered (Fig. 3c). Most notably, the keto-modified polyethylenes possess high molecular weights (up to $\mathrm{M}_{\mathrm{w}} \sim 400.000 \mathrm{~g} \mathrm{~mol}^{-1}, \mathrm{M}_{\mathrm{n}} \sim 220.000 \mathrm{~g}$ $\mathrm{mol}^{-1}$ ). This is remarkable in view of the very low molecu- 
lar weights formed in ethylene-CO copolymerizations yielding any partially non-alternating motifs to date, ${ }^{19}$ and it is crucial to obtain useful mechanical properties. Indeed, tensile tests on injection molded test bars show a ductile behavior that compares to commercial HDPE (Fig. 3d).
The modulus of elasticity and tensile strength compares to that of typical linear polyethylenes $(\mathrm{E}=995 \mathrm{MPa}$ and $\sigma_{\mathrm{y}}=29 \mathrm{MPa}$, compared to literature values of $\mathrm{E}=900 \mathrm{MPa}$ and $\sigma_{\mathrm{y}}=27 \mathrm{Mpa}$ for HDPE and for LDPE E $=240 \mathrm{MPa}$, $\left.\sigma_{\mathrm{y}}=12 \mathrm{MPa}\right)^{28}$

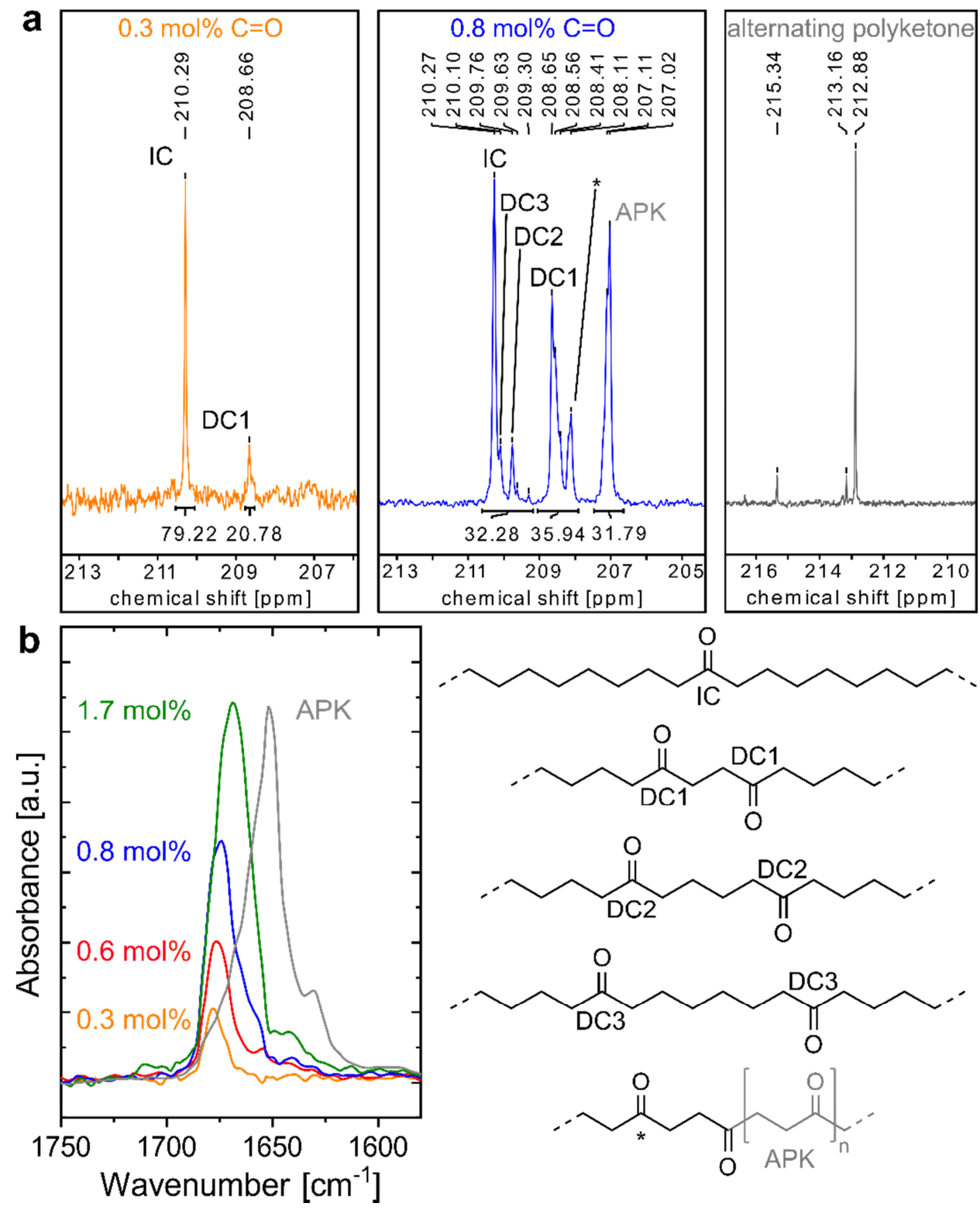

Fig. 2. Microstructure Characterization of Copolymers. a, Carbonyl regime of ${ }^{13} \mathrm{C}$ NMR spectra of ${ }^{13} \mathrm{CO}$ copolymers with different keto contents $\left(\mathrm{C}_{2} \mathrm{D}_{2} \mathrm{Cl}_{4}\right.$ solvent, $\left.383 \mathrm{~K}\right)$ and an alternating polyketone (hexafluoroisopropanol/ $\mathrm{C}_{6} \mathrm{D}_{6}$ solvent, $273 \mathrm{~K}$ ) for comparison. IC: Isolated carbonyl, DCX: Double carbonyl separated by X repeat units of ethylene, APK: Alternating polyketone, *: Carbonyl adjacent to an alternating sequence $\mathbf{b}$, IR spectra of copolymers with different keto contents, and alternating polyketone for comparison. The absorbance intensity of alternating polyketone is adjusted for clarity. Note these are ${ }^{13} \mathrm{CO}$ copolymers as in a, which shifts the absorption frequency compared to non-labelled copolymers (cf. the Supporting Information for IR spectra of the latter).

No evidence for undesirable cross-linking that could hamper melt processing was observed. This is notable as cross-linking promoted by the keto motifs is an issue in the thermoplastic processing of commercial polyketone resins. $^{29}$
Mechanistic features of the catalytic polymerization. At given initial reaction conditions, the composition of the formed polymer does not vary significantly with increasing reaction time and increasing polymer yield (entries 2 to 4 and 10 to 12). A homogeneous material is formed, as op- 
posed to a conceivable drift of microstructure and composition due to e.g. a significant alteration of the monomers' relative concentrations. Compared to ethylene homopolymerization the copolymerization yields and average activities are lowered (entry 2 vs. 23, cf. Table S1 in the Supporting Information for further homopolymerization data). However, this is not due to a conceivable problematic rapid catalyst deactivation. Catalysts are stable for hours in $\mathrm{CO}$ copolymerizations (entries 2 to 4). Presumably, in addition to $\mathrm{CO}$ binding, reversible chelating binding of formed keto groups slows down chain growth to a certain extent as concluded from the observation of overall increased productivities with increasing monomer concentration at a given E/CO ratio (entries 2 vs. 7 and 9 vs. 11. Cf. Figure $\mathrm{S} 33$ in the SI for a scheme of reversible deactivation path- ways). A certain polymerization reaction temperature is required to overcome this retardation. Thus, efficient copolymerization with 2 requires ca. $100{ }^{\circ} \mathrm{C}$, while homopolymerizations proceed rapidly also at lower temperatures (entry 24). As anticipated, higher polymerization reaction temperatures also decrease the $\mathrm{CO}$ incorporation and in fact are necessary to achieve non-alternation (entry 8 vs. 2 to 7 ). This underlines the role of the temperature stability of catalysts $\mathbf{2}$ to 7 in enabling the non-alternating copolymerizations to keto-modified polyethylenes. Beyond this, the underlying phosphinophenolate motif also appears particularly suited for non-alternating copolymerization. By comparison, $\mathbf{1}$ also at an elevated polymerization temperature only formed alternating polyketone (entry 22).
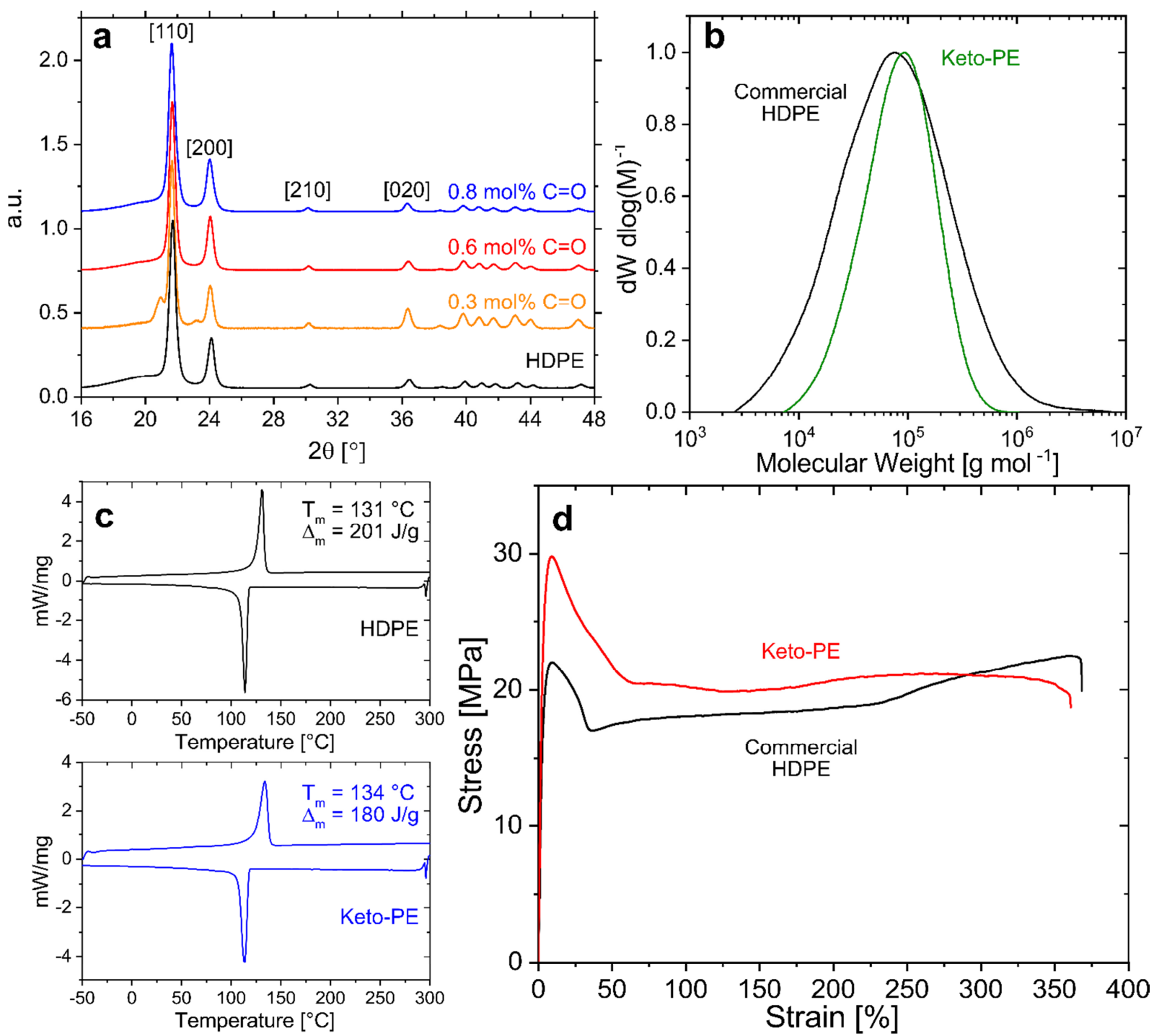

Fig. 3. Materials Characterization of Copolymers. a, WAXS of copolymers with different keto contents and commercial HDPE. Reflexes correspond to the orthorhombic unit cell of polyethylene. $\mathbf{b}$, GPC trace of copolymer (1.0 mol\% keto repeat units), and commercial HDPE for comparison. c, DSC trace of copolymer ( $0.8 \mathrm{~mol} \%$ keto repeat units), and commercial HDPE for comparison. d, Representative stressstrain curves of injection molded keto-modified polyethylene ( $0.6 \mathrm{~mol} \%$ keto repeat units) in comparison to commercial HDPE. 
The high molecular weights of the keto-modified polyethylenes suggest that the presence and incorporation of $\mathrm{CO}$ does not promote any problematic chain transfer reactions. Indeed, an analysis of the polymers' endgroups shows only those types of endgroups also found in homopolyethylenes, namely olefinic endgroups originating from $\beta$-hydrogen transfer of the Ni-polymeryl species (Figure S19). This confirms no undesired additional chain transfer pathways are operative in CO copolymerizations. Rather, the presence of $\mathrm{CO}$ appears to hinder chain transfer and branching as concluded from higher molecular weights and the complete absence of branches in copolymers compared to ethylene homopolymers (entry 23 vs. 2 to 4 and 9; and Figures S19, S20, S24 and S25), possibly by blocking of coordination sites for $\beta$-hydrogen transfer by $\mathrm{CO}$.

\section{Conclusion}

In summary, the non-alternating copolymerization of ethylene with carbon monoxide to in-chain keto functionalized polyethylene materials can be achieved with catalysts based on nickel as the active sites. Remarkably, this longsought reaction proceeds under mild conditions, namely ethylene pressures of 5 to $10 \mathrm{~atm}$ or lower. The high catalyst stability and well-behaved single site nature of the catalysts in the presence of the carbon monoxide monomer - which usually deactivates olefin polymerization catalysts rapidly and irreversibly - during the generation of the target polymers is encouraging for the further prospects of this reaction. The earth-abundant nature of nickel compared to noble metal catalysts, as used e.g. for polyketone production, is further beneficial. The ability to polymerize at elevated temperatures is identifed to be a key feature of suitable catalysts for non-alternating copolymerization, which can guide further catalyst development. Other than apprehended from polar vinyl monomer copolymerizations, ${ }^{14,25,26}$ the incorporation of carbon monoxide does not compromise polymer molecular weights. On the contrary, the presence of carbon monoxide suppresses chain transfer and branching. This is important and encouraging for further development of these novel materials, given the paramount role of sufficient molecular weight in attaining desirable mechanical properties. The now provided access to in-chain functionalized polyethylene which possess the desirable materials properties of HDPE offers perspectives for environmentally less persistent polyolefins in enabling photolytic and oxidative chain breakdown.

\section{ASSOCIATED CONTENT}

Supplementary Information. Precatalyst synthesis and characterization, experimental methods and additional copolymer analysis data Fig. S1 - Fig. S33.

\section{AUTHOR INFORMATION}

Corresponding Author

*E-mail: Stefan.Mecking@uni-konstanz.de

\section{Author Contributions}

S.M. conceived the concept. M.B., F.L., T.M., L.O and S.M. jointly devised the experimental programm. F.L., M.B. and T.M. synthesized and characterized catalyst precursors. M.B. and T.M. performed polymerization experiments with phosphinenolato catalysts. L.O. performed experiments with salicylaldimine catalysts. M.B. and T.M. performed microstructure analysis, and experiments on materials properties. All authors jointly wrote the manuscript.

\section{Notes}

The authors declare no competing financial interests.

\section{ACKNOWLEDGMENT}

We thank Inigo Göttker-Schnetmann for support with NMR data interpretation, Marcel Eck and Manuel Häußler for support with polymer processing, Lars Bolk for DSC and GPC measurements and Robin Kirsten for technical support. Funding of our studies on degradable polyethylenes by the ERC (Advanced Grant DEEPCAT, No. 832480) is gratefully acknowledged.

\section{REFERENCES}

1) Stürzel, M.; Mihan, S.; Mülhaupt, R. From Multisite Polymerization Catalysis to Sustainable Materials and All-Polyolefin Composites. Chem. Rev. 2016, 116, 1398-1433. doi: 10.1021/acs.chemrev.5b00310

(2) Strobl, G. R. The physics of polymers: Concepts for understanding their structures and behavior, 3rd. edn.; Springer: Berlin, Heidelberg, 2007. doi: 10.1007/978-3-540-68411-4

(3) Morgen, T. O.; Baur, M.; Göttker-Schnetmann, I.; Mecking, S. Photodegradable branched polyethylenes from carbon monoxide copolymerization under benign conditions. Nat. Commun. 2020, 11, 3693. doi: 10.1038/s41467-020-17542-5.

(4) Hartley, G. H.; Guillet, J. E. Photochemistry of Ketone Polymers. I. Studies of Ethylene-Carbon Monoxide Copolymers. Macromolecules 1968, 1, 165-170. doi: 10.1021/ma60002a012

(5) Andrady, A. L.; Pegram, J. E.; Song, Y. Studies on enhanced degradable plastics. II. Weathering of enhanced photodegradable polyethylenes under marine and freshwater floating exposure. $J$. Environ. Polym. Degr. 1993, 1, 117-126. Doi. 10.1007/BF01418205

(6) Ortmann, P.; Wimmer, F. P.; Mecking, S. Long-Spaced Polyketones from ADMET Copolymerizations as Ideal Models for Ethylene/CO Copolymers. ACS Macro Lett. 2015, 4, 704-707. doi: 10.1021/acsmacrolett.5b00324

(7) Rix, F. C.; Brookhart, M.; White, P. S. Mechanistic Studies of the Palladium(II)-Catalyzed Copolymerization of Ethylene with Carbon Monoxide. J. Am. Chem. Soc. 1996, 118, 4746-4764. doi: 10.1021/JA953276T

(8) Drent, E.; Budzelaar, P. H. M. Palladium-Catalyzed Alternating Copolymerization of Alkenes and Carbon Monoxide. Chem. Rev. 1996, 96, 663-682. doi: 10.1021/cr940282j

(9) Piovano, A.; Zarupski, J.; Groppo, E. Disclosing the Interaction between Carbon Monoxide and Alkylated $\mathrm{Ti}^{3+}$ Species: a Direct Insight into Ziegler-Natta Catalysis. J. Phys. Chem. Lett. 2020, 11, 5632-5637. doi: 10.1021/acs.jpclett.0c01665.

(10) Bertleff, W.; Roeper, M.; Sava, X. Carbonylation. Ullmann's Encyclopedia of Industrial Chemistry; Wiley-VCH Verlag GmbH \& Co. KGaA: Weinheim, Germany, 2012, pp 73-97. doi: 10.1002/14356007.a05_217.pub2

(11) Chen, Z.; Brookhart, M. Exploring Ethylene/Polar Vinyl Monomer Copolymerizations Using $\mathrm{Ni}$ and $\mathrm{Pd} \alpha$-Diimine Catalysts. Acc. Chem. Res. 2018, 51, 1831-1839. DOI: 10.1021/acs.accounts. 8 b00225 
(12) Tan, C.; Chen, C. Emerging Palladium and Nickel Catalysts for Copolymerization of Olefins with Polar Monomers. Angew. Chem. Int. Ed. 2019, 58, 7192-7200. DOI: 10.1002/anie.201814634

(13) Keyes, A.; Basbug Alhan, H. E.; Ordonez, E.; Ha, U.; Beezer, D. B.; Dau, H.; Liu, Y.-S.; Tsogtgerel, E.; Jones, G. R.; Harth, E. Olefins and Vinyl Polar Monomers: Bridging the Gap for Next Generation Materials. Angew. Chem. Int. Ed. 2019, 58, 12370-12391. DOI: 10.1002/anie.201900650

(14) Nakamura, A.; Ito, S.; Nozaki, K. Coordination-Insertion Copolymerization of Fundamental Polar Monomers. Chem. Rev. 2009, 109, 5215-5244. doi: 10.1021/cr900079r

(15) Drent, E.; van Dijk, R.; van Ginkel, R.; van Oort, B.; Pugh, R. I. The first example of palladium catalysed non-perfectly alternating copolymerisation of ethene and carbon monoxide. Chem. Commun. 2002, 964-965. doi: 10.1039/b111629k

(16) Chen, C.; Anselment, T. M. J.; Fröhlich, R.; Rieger, B.; Kehr, G.; Erker, G. $o$-Diarylphosphinoferrocene Sulfonate Palladium Systems for Nonalternating Ethene-Carbon Monoxide Copolymerization. Organometallics 2011, 30, 5248-5257. doi: 10.1021/om200628r

(17) Bettucci, L.; Bianchini, C.; Claver, C.; Suarez, E. J. G.; Ruiz, A.; Meli, A.; Oberhauser, W. Ligand effects in the non-alternating CO-ethylene copolymerization by palladium(II) catalysis. Dalton Trans 2007, 5590-5602. doi: 10.1039/b711280g

(18) Newsham, D. K.; Borkar, S.; Sen, A.; Conner, D. M.; Goodall, B. Inhibitory Role of Carbon Monoxide in Palladium(II)-Catalyzed Nonalternating Ethene/Carbon Monoxide Copolymerizations and the Synthesis of Polyethene-blockpoly(ethene-alt-carbon monoxide). Organometallics 2007, 26, 3636-3638. doi: 10.1021/om700523m.

(19) Soomro, S. S.; Cozzula, D.; Leitner, W.; Vogt, H.; Müller, T. E. The microstructure and melt properties of CO-ethylene copolymers with remarkably low CO content. Polym. Chem. 2014, 5, 3831-3837. doi: DOI: 10.1039/C3PY01637D

(20) Mecking, S.; Schnitte, M. Neutral Nickel(II) Catalysts: From Hyperbranched Oligomers to Nanocrystal-Based Materials. Acc. Chem. Res. 2020, 53, 2738-2752. doi: 10.1021/acs.accounts.0c00540.

(21) Keim, W. Oligomerization of ethylene to $\alpha$-olefins: discovery and development of the shell higher olefin process (SHOP). Angew. Chem. Int. Ed. 2013, 52, 12492-12496. doi: 10.1002/anie. 201305308

(22) Ostoja Starzewski, K. A.; Witte, J. Control of the molecular weight of polyethylene by synthesis with diylide nickel catalysts. Angew. Chem. Int. Ed. 1987, 26, 63-64. doi: 10.1002/anie. 198700631

(23) Klabunde, U.; Ittel, S. D. Nickel catalysis for ethylene homoand copolymerization. J. Mol. Catal. 1987, 41, 123-134. doi: 10.1016/0304-5102(87)80023-8

(24) Keim, W.; Kowaldt, F. H.; Goddard, R.; Krueger, C. New coordination mode of (benzoylmethylene)triphenylphosphorane in a nickel oligomerization catalyst. Angew. Chem. Int. Ed. 1978, 17, 466-467. doi: 10.1002/anie.197804661

(25) Xin, B. S.; Sato, N.; Tanna, A.; Oishi, Y.; Konishi, Y.; Shimizu, F. Nickel Catalyzed Copolymerization of Ethylene and Alkyl Acrylates. J. Am. Chem. Soc. 2017, 139, 3611-3614. doi: 10.1021/jacs.6b13051

(26) Zhang, Y.; Mu, H.; Pan, L.; Wang, X.; Li, Y. Robust Bulky $[\mathrm{P}, \mathrm{O}]$ Neutral Nickel Catalysts for Copolymerization of Ethylene with Polar Vinyl Monomers. ACS Catal. 2018, 8, 5963-5976. doi: $10.1021 /$ acscatal.8b01088
(27) Stafford, C.; Arndtsen, B. A. Synthesis of neutral nickelmethyl complexes with monodentate imines and their sequential insertion of carbon monoxide and imine. Inorg. Chim. Acta 2011, 369, 231-239. doi: 10.1016/j.ica.2010.12.024

(28) Jeremic, D. Polyethylene. Ullmann's Encyclopedia of Industrial Chemistry; Wiley-VCH Verlag GmbH \& Co. KGaA: Weinheim, Germany, 2014; pp 1-42. doi: 10.1002/14356007.a21_487.pub3

(29) Ash. C. E. Ash, C. E.; Waters, D. G.; Smaardijk, A. A. Synthesis and stability of aliphatic polyketones. Annu. Tech. Conf. Soc. Plast. Eng. 1995, 53, 2319-2325. 